\title{
Elementary School Teachers and Mathematics: Communities of Practice and an Opportunity for Change
}

\author{
Laura M. Gellert ${ }^{1}$ \\ ${ }^{1}$ Department of Teaching, Learning and Culture, The City College of New York, USA \\ Correspondence: Laura M. Gellert, Department of Teaching, Learning and Culture, The City College of New \\ York, USA. E-mail: lgellert@ccny.cuny.edu
}

\author{
Received: July 30, 2013 Accepted: August 30, $2013 \quad$ Online Published: November 12, 2013 \\ doi:10.5539/jel.v2n4p113 URL: http://dx.doi.org/10.5539/jel.v2n4p113
}

\begin{abstract}
This paper investigates the transformation of new elementary teachers in their understanding of mathematics in relation to pedagogy and learning. By participating in an intentionally created community of practice, new elementary school teachers, began to connect to mathematics in new ways: reflectively, confidently, and inquisitively. Analysis focused on data from teacher reflections, observations, group meetings, and revealed communities of practice in which an increased confidence with mathematics and teaching mathematics developed. Through the course of the community of practice, the participants began to think of themselves as mathematics teachers, mainly through their ability to reflect, question, and take ownership of their practice.
\end{abstract}

Keywords: elementary school teachers, Mathematics, communities of practice

\section{Introduction}

For most elementary school teachers, mathematics is not their main subject strength, although they are responsible for teaching the foundations that will help students develop their mathematical knowledge. A richer content knowledge for teachers leads to greater comfort with mathematics, and as a result increases student achievement (Ball \& Wilson, 1990; Darling-Hammond, 1996; Hill, Rowan, \& Ball, 2005; McDiarmid \& Wilson, 1991). A teacher's pedagogical knowledge and mathematical content knowledge have been shown to be of great importance in conjunction with a teacher's mathematics knowledge for teaching (Ball, 2003). Mathematics knowledge for teaching has been defined by Hill et al. (2005) as the knowledge necessary to teach mathematics and understand students' mathematical thinking, for example, explaining concepts, interpreting student work, and working with and adjusting textbook representation of topics. The most recent position of the National Council for Teachers of Mathematics (NCTM, 2008) holds that teachers should be able to impart knowledge in addition to becoming facilitators of student learning. Furthermore, teachers must choose appropriate tasks leading to differentiated questioning that challenges all students in the learning of mathematics and nurtures the students' mathematical thinking and reasoning processes (Common Core State Standards Initiative, 2010; NCTM, 2000; NCTM, 1991).

Reforms are part of the institutional structures and context in which new elementary school teachers begin their teaching profession. Since 2000, reforms that have had an impact on teachers and the teaching of mathematics have been implemented for a variety of reasons. Some of the reforms that have been instituted are alternative certification programs to get more teachers into hard-to-staff schools beyond the traditional routes, subject-specific mentors such as mathematics coaches, professional development programs that continue the education of teachers while in-service, and standardized mathematics curricula and assessments. While mentioning different types of reforms may help to give context to the type of environment that elementary school teachers are teaching in, it does not give the entire picture.

A strong mathematical content and pedagogy knowledge and the confidence that comes with this strength can be defined as a "positive identity for mathematics." This study shows how this positive identity emerged through involvement in an intentionally created community of practice. By using individual cases of teacher's practice, reflection, and involvement in a community of practice, I was able to understand how the experiences and identities of new elementary school teachers change in relation to the teaching, learning and understanding of mathematics. The structures (curricula, mentoring supports, experiences) that influence practice in relation to these teachers as mathematics teachers are part of the context. Most importantly, this study sheds light on the 
following question: "Given the known difficulties involved in beginning a teaching career, how can a community of practice help to establish more positive mathematics identities for elementary school teachers?"

\section{Theoretical Framework}

The use of communities of practice to inform the study of identity as transformative and socially constructed has been found to be beneficial for teacher education (Lave \& Wenger, 2003). The use of a community of practice model, a construct in which participants engage in collective learning that is supported by the pursuit of common goals and social interactions (Wenger, 1998), is a missing support structure for many new teachers. Communities of practice can give teachers the opportunity to continue their study of teaching (Feiman-Nemser, 2001) through involvement with others. I was able to study the growth of the teachers, specifically their transforming identities, by observing an intentionally created community of practice. I use the term "identity" to help explain teacher development and learning by which the teachers I worked with developed into "teachers of mathematics." A number of scholars have used the term "identity" to help explain teacher development and learning (Enyedy, Goldberg, \& Welsh, 2006; Gee, 2000-2001; Lave \& Wenger, 2003; Sfard \& Prusak, 2005; Tobin \& Roth, 2007; and Wenger, 1998). These scholars' ideas about identity interconnect. I used identity theory to help to understand the identity transformation of the teachers I worked with into "teachers of mathematics." Based on the work of these scholars, I would characterize the work of identity as follows:

- Identity is dynamic.

- Identity is socially constructed - a cultural study of the person in practice.

- Identity is also internally constructed - but in relation to others.

- Identity is influenced by one's actions - experience becomes meaning.

For new teachers, learning is usually individual, unfocused, and superficial. Discomfort that many elementary school teachers have with mathematics may be explained using identity theory. The identity one has works in conjunction with one's practice; a discomfort in mathematics can be seen in the practice of mathematics.

Initially, learning theories can be regarded as how people learn in practice, i.e., what is the learning process for the participants involved? What people do in practice influences how people learn (Dewey, 1997/1933; Vygotsky, 1978). If the practice is designed to further learning, then it involves "overcoming the inertia that inclines us to accept suggestions at their face value" (Dewey, 1997/1933, p. 13). To be put in a situation of reflective thought leads to uncertainty and then further inquiry. Vygotsky writes about how social interactions are central to how we learn, reflect, and change; and although the development of the child's mind is central to his theory in Mind in Society (1978), his ideas can be applied to observe how people think and learn in social situations.

These social situations in which participants talk together, work together, generate ideas, build on others' ideas, reason, explore, and discover together are reflective learning environments and examples of the concepts presented above. Teachers who are aware of the necessity for reflection and inquiry can experience what Franke, Carpenter, Fennema, Ansell, and Behrend (1998) refer to as "self-sustaining generative change." This reflection and change in the teachers' learning occurs in practice either in the classroom or with a group of fellow teachers (Wood, Cobb, \& Yackel, 1991). Rather than functioning in isolation, teachers, in this view, learn in a social environment (Carpenter, Fennema, \& Franke, 1996). This reflection leads to connecting mathematics to the teacher and then to the student, which is important to learning the material (Dewey, 1990/1915; Saxe, 2002; Vygotsky, 1978). These arenas for reflection among teachers help build the skills teachers should have in their teaching. "Teachers learn best by studying, doing and reflecting, by collaborating with other teachers, by looking closely at students and their work and by sharing what they see" (Darling-Hammond, 1998, p. 1). Moreover, having strength and comfort in mathematics and mathematics knowledge for teaching is essential for teachers if they are to have the ability to modify their teaching and assessments and to make sound judgments (Ball, 2003).

The use of reflection in a teacher's development has been supported for almost a century, but its importance increases and decreases with other trends in teacher development. Dewey $(1997 / 1933)$ originally wrote that the purpose of teacher education was to inform and educate teachers on their practice. He modeled his ideas about teacher education on the reflective practitioner who identifies problematic situations and modifies his or her practice to fit the situation. Ball (1996) stresses that a certain type of knowledge for teaching is the ability to reflect on the teaching. Other models of reflection are based on using tools for reflection, such as video clubs, professional learning communities, and lesson study, where teachers reflect on teaching while discussing specifics about teaching in the context of the classroom (Education Week, 2007; Sherin \& van Es 2005; Stigler $\&$ Hiebert, 1999). This theoretical framework will be connected to a community of practice of new elementary 
school teachers and their individual experiences outside the formal community of their schools as this experience relates to mathematics.

\section{Methodology}

In creating a laboratory to study teacher practice in the teaching of mathematics, teacher reflection, and teacher identity, I formed a community of practice that served as a forum where teachers could work on aspects of their mathematics teaching. Three new (first- and second-year) elementary school teachers volunteered to participate in this qualitative study after responding to a mass mailing to students in the Master's degree program in childhood education at a local university. Before the first observation of a class taught by each teacher, the teacher completed a participant history survey (Cooley et al., 2006). This survey supplied information regarding the participants' mathematics background based on mathematics courses taken at both the secondary school and post-secondary school levels. Other demographic information about the teachers was gathered from the survey, such as college attendance and degree, information about the school at which they were teaching, and information about the graduate teacher education program in which they were enrolled at the time of the study. Life story interviews (Drake, Spillane, \& Huffer-Ackles, 2001; McAdams, 1993) provided insight into the participant's initial experiences and beliefs about mathematics.

The three participants were observed and videotaped in their mathematics classrooms twice a month over the course of five months, with the researcher taking on the role of participant observer. After each observation, the researcher conducted an informal interview with the teacher about the class observed, and both the participant and the researcher wrote reflective journals. During the mathematics classes, the researcher, an experienced mathematics educator, was involved in the class as an additional resource and mentor for the teacher.

Once a month for four months, the teachers met in a group with the researcher. These meetings were used to further the professional development of these new teachers in the teaching and learning of mathematics. Each meeting consisted of observing and discussing the video clips of the teaching of each of the three teachers. The researcher and the participant whose class was observed chose these clips together, based on criteria including mathematical content, use of the standardized curriculum or the chosen text, and organization of the curriculum. The researcher brought supplementary areas of discussion to the table such as mathematical problem solving and structures influencing teaching. The group meetings were videotaped to serve as an additional data source. Throughout the study, email correspondence became another form of informal communication that served as both a reflective and an interview vehicle. A final source of data was an additional journal kept by the researcher reflecting on the group meetings.

The methods for data analysis focused on the teachers' reflection on and practice of their mathematics teaching and how the intentionally formed community supported the teachers' development and transformation as mathematics teachers. More specifically, coding consisted of looking at the participants' journal entries for "I" and "They" statements in relation to how they described the teaching for a given day. The "I" and "they" discourse codes emerged as indicators of ownership, reflection, confidence, and inquiry. The specific discourse that occurred in response to watching the video clips during the group meetings was coded to find themes illustrating how the participants discussed their teaching and learning of mathematics.

\section{Participants}

Below I provide a brief portrait of each teacher, a description of his or her teaching situation, and a characterization of his or her initial math-teacher identity to help to provide the context in which the participants' initial experiences and ideas about mathematics inform the study. The three teachers in this study were pursuing their Masters degrees in education from the same university. Two of the participants (Jessica and Julia) were getting their Masters in childhood education while participating in the New York City Teaching Fellows Program (an alternative certification program). The third participant (James) had completed his undergraduate degree in childhood education, obtaining initial certification, and was pursuing his Masters degree in childhood education with a math specialty. Jessica taught third grade in a large urban elementary school in the southeast section of the city; Julia taught fifth grade in a large urban elementary school in the eastern part of the city; and James taught third grade in a small elementary school in the eastern part of the city.

\subsection{Jessica}

Jessica, an African American female, is a recent graduate of a New England liberal arts college, having majored in sociology. The New York City Teaching Fellows program gave her an opportunity to work for a middle class African American community that was similar to the one she grew up in. As a first-year teacher in a large urban elementary school, Jessica was given the opportunity to share her interest in mathematics with children. 
The student composition of Jessica's school was about 95 percent African American, and there were about 175 students in the third grade. About 65 percent of the students at this school scored at the proficient level or above on the New York State assessment in mathematics. Jessica's class consisted of about twenty third graders.

As the year progressed, Jessica began to find it difficult to work at the school, mainly because of decisions made by the administration (e.g., disbanding the step club, an after-school activity), but she continued to enjoy collegiality with her colleagues. She mentioned that her math coach met with her on a consistent basis and helped with planning and pacing, but Jessica still felt that she needed more support than she was getting from the school administration and staff.

\subsection{Julia}

Julia, a white female, recently graduated from a small liberal arts college in the Midwest, having majored in public relations and theology. Also, a New York City Teaching Fellow, Julia stated that she never actually had a desire to be a teacher, though she knew that she wanted to work in a "profession of service." She began her first year of teaching at a large urban elementary school in an immigrant community where over three-quarters of the student population was Hispanic or Asian and 15 percent were recent immigrants. At the beginning of the school year, Julia's fifth grade class had twenty-five students, but after March, she received three new students when another teacher left the school. Most of the students in her class had scored proficient or above on the New York State assessment in mathematics.

Julia came to teach at her school through a connection that she made through her summer student teaching placement. Her interest in mathematics made her want to teach high school mathematics but, because of her lack of undergraduate mathematics coursework, she did not fit the requirements and found elementary school mathematics to be her only option. Julia found that the New York City Teaching Fellows Program offered a more competitive salary than other alternative certification teaching programs that she investigated around the country.

\subsection{James}

James, a Hispanic male, recently graduated from a local college after taking some time off between high school and college. He majored in education with a concentration in theater at the elementary school level. As a second-year teacher of the third grade at a small urban elementary school, James was becoming a solid fixture in his school community. The student population of the school was 70 percent Hispanic and 25 percent African American. There were more than 100 students in the third grade and about 65 percent of the students at this school scored proficient or above on the New York State mathematics test (2004-2005 DOE Annual school report). James had approximately twenty-five students in his class, in a classroom that appeared cramped.

The stability of the job and his love for children led him to the profession of teaching. Having completed student teaching at a local elementary school, James thought he would be teaching there after graduation, but because his certificate did not arrive in time, the principal would not hire him. Two weeks before school started, James walked around to schools in the same area with résumé in hand and was offered a job as a walk-in at his current school. He is pleased with how it all worked out. At the time of the study, James had initial certification to teach in the schools and needed to obtain his Master's degree within five years.

\section{Findings}

In analyzing these data sets, patterns and themes emerged that helped to describe these teachers as mathematics learners and teachers. These patterns and themes are identified through the discourse between the researcher and these teachers, both in the teachers' mathematics classes and in the group meetings where they reflected on their classes and teaching. The participants' confidence with mathematics, reflective practice, and the questioning process are displayed in their discussions about mathematics and mathematics teaching. The critical themes that emerged from the analysis, and are discussed in detail below, are the teaching of mathematics, mathematics learning and understanding, and mathematics identity. These themes and patterns are influenced by the role of the community of practice in the teachers' learning and professional growth.

\subsection{Teaching of Mathematics}

As the participants watched the video clips, their comments changed from more superficial to more critical. Using research on new teachers' practice (Ball \& Wilson, 1990; Warfield, et al., 2005; Wilson \& Ball, 1991) I analyzed participants" variations in self-confidence. The discourse was analyzed for instances of "I" statements or "they" statements as a way of demonstrating variations in self-confidence. The participants' use of different statements shows whether they felt sufficiently comfortable to make decisions in their mathematics teaching. 
Initially, the teachers commented on how much they liked how something looked, but as the meetings progressed the teachers became more critical about what they were watching and specific about the mathematics. For example, while watching the first video clip of Julia, James commented, "she has a colorful room..." (James group meeting 3/1/07). This comment was made in relation to how "they," the administration in their district, liked rooms to be set up. At the last group meeting, James commented about Julia's teaching, "Her questioning was directed." This comment continued with how this type of questioning was "successful in my classroom" (James group meeting 5/29/07). James became more critical and reflective in teaching while working with other teachers in the context of classroom teaching (Sherin \& van Es, 2005; Warfield, et al., 2005).

Further variations in confidence in mathematics teaching were demonstrated in how Julia viewed the curriculum and the learning of mathematics in relation to her students, who overall had good computational skills but tended not to think about the concepts.

From what I have learned so far, Everyday Math's spiraling introduces concepts to children in each grade and doesn't plan for mastery of a topic until a later grade. With my students however, since they are so advanced, I believe that this curriculum can be troublesome for them because they don't need the spiraling in this way. They know how to add and subtract fractions already. The students who do tend to appreciate the new methods of solving are those handful that came to this class with a weaker foundation, (Julia, Reflection, 1/5/07).

After finishing her first year, Julia began to see how her teaching was changing due to her questioning the curriculum and developing a greater understanding of the benefits for her students. She began her second year feeling more confident in her mathematics teaching, "I feel like I really know what I am doing for once!" (Julia, email correspondence, 10/19/07). The initial questioning and uncertainty with the curriculum began to transform into a greater confidence and certainty with the written math (Remillard, 2000).

Furthermore, Julia began to take more ownership of how she worked with the curriculum. She attributed her ability to question the material and do what works best for her students to her own better understanding of teaching mathematics and mathematics in general

Fractions seem to be going better, but that's because I really pulled apart the Unit and taught it my own way. Instead of teaching ordering fractions and decimals at the beginning, I waited until they understood how to go from fraction to decimal. The use of visuals has been very powerful, (Julia, email correspondence, 12/8/2007).

This strength and comfort in the mathematics and even in mathematics knowledge for teaching led to Julia modifying her teaching and instructional methods (Ball, 2003).

Jessica did not express as much enthusiasm or strong feelings about teaching mathematics, but she did say that mathematics is one of her favorite subjects to teach, "I feel like [mathematics] is concrete enough to be easy for me to relay information and yet abstract ideas and thinking can be added to it to make it more interesting and thought-provoking" (Jessica's Participant History Survey, February 2007). As the term progressed, Jessica began to reflect more on her teaching of mathematics "I just feel like this [lesson] was not as drawn out [as the follow-up lesson] and [it] had many more moments where I was really teaching” (Jessica, e-mail correspondence, $3 / 27 / 07$ ). Jessica's comparison was between two consecutive lessons for the same mathematical topic. In the first lesson, Jessica introduced her students to word sentences using addition and subtraction with parentheses. This lesson followed the Everyday Mathematics (2004) text very closely and, as Jessica mentioned in her e-mail message, gave her opportunities for teachable moments. The second lesson was more abstract as there was not a single answer to the problems. The students were asked to determine how many different ways and in what ways to score 10 points in a basketball game using 3,2, and 1-point baskets. The students in the class seemed to understand the mathematics behind the activity. However, Jessica believed that she spent much more time in class explaining how to organize their thinking in a table format then discussing the mathematics. Although, Jessica's uncertainty with the mathematics made it more difficult for her to incorporate a discussion of the mathematics in a more abstract setting, she was able to recognize the differences in her teaching of mathematics during both lessons.

\subsection{Mathematics Learning and Understanding}

Through an analysis of the discourse during the group meetings relating to the topics of mathematics pedagogy and learning, a transformation in the participants' confidence with mathematics and the teaching of mathematics began to emerge. Julia's enthusiasm about teaching mathematics was apparent from the beginning, "Just as when I was a student, I love math! I love teaching it, and when I do a lesson I really feel like I understand it better. I love explaining things to kids so they understand it," (Julia's Participant History Survey, December 2007). This initial enthusiasm began to conflict with how mathematics learning was playing out in her classroom. Many of 
her students wanted to finish the work quickly and she wondered how to keep them academically motivated and involved while not letting other students who needed some help slip through the cracks. Her concern is supported by how she sees mathematics: "Math is a process of exploration and requires active engagement and carefully planned discovery," (e-mail correspondence, 5/30/07). Julia's understanding of mathematics pedagogy and the mathematics understanding of her students are in conflict; her view of mathematics as a process of exploration was challenged by her students' idea of mathematics as solving computational problems quickly. The challenge for Julia was to acquire greater strength in a mathematical knowledge for teaching to enforce her pedagogy views (Ball \& Wilson, 1990).

Another theme that emerged was the increased reflection leading to a different or new understanding of mathematics teaching. While looking at lessons on non-traditional algorithms, the participants began with comments like "ugh, partial sum, it totally messes up kids who know how to do the algorithm," (Jessica, group meeting 2,3/29/07). Jessica is referring to the standard multiplication algorithm. As the discussion continued and the teachers began to look at the text more closely, some of their comments showed a greater understanding of the thoughts behind the curriculum and a transformed view of the mathematics.

Jessica: Now, that I look at this I think that it reinforces place value.

Jessica: Kids, I feel, still struggle with place value in March and so, I think it is interesting that they don't put it in...

James: But, it is one of the standards though, understanding the place value structure, see it is in line with the New York State standards. (James is very fluent with the State content and process standards.)

Jessica: Yeah.

James: I agree with you, that it does reinforce place value, but I would not do the hundreds first, I would get them in the habit of doing the ones first so just how they are doing it here, I would have them start from this side. (Pointing to a problem in the text.)

Julia: I was just going to say that because that would alleviate the problem.

Jessica: And then that is how you add in real life.

James: Yeah, without regrouping this is adding without regrouping.

Jessica: Right, because does this apply when you regroup? It does, because say this was 3 and 7 it would just be 10 and 9 and 5 would be 14 .

James: That is why the base ten blocks are good, because 13 tens what do I do with 13 tens I could use one flat and 3 tens, ... regrouping without using the word regrouping. ... I think it is a strong lesson I would just change it from right to left.

The Researcher: Why, why would you change it from right to left?

James: So they won't develop any bad habits when they get into the real algorithm.

The Researcher: do you expect them to do use this algorithm later on?

Jessica: Not really.

The Researcher: Never?

James: I kind of want to get away from it.

The Researcher: Why?

Jessica: I mean I think we are biased.

James: I think so.

Jessica: because of how we learned and how everybody learned until Everyday Math, so...

The discussion continued with my input about one possible benefit of using this partial sum algorithm for enforcing estimation. Toward the end of the conversation, the participants began to reflect on the fact that they actually used the partial sum algorithm informally especially in relation to estimation. For example, after a bit of discussion, Jessica confidently stated, "oh yeah, I do that too, when I am calculating a tip, I do the 10 percent first and then the 5 percent and add them together." (Group Meeting 2,3/29/07). The use of a situation in which the participants were able to talk about the mathematics and teaching enabled them to reflect on their own understanding of mathematics (Franke, et al., 1998; Wood, et al., 1991). Through questioning, reflection, and an 
increased confidence in their practice, these new elementary school teachers began to connect to mathematics less at a superficial computational level and more at a deeply conceptual level.

The previous example of what happened at the moment of discussion in the community of practice demonstrates the transforming views of the participants, but what is even more telling is what happened a month later for James and a couple of months later for Jessica and Julia. James reflected on the curriculum and mathematics teaching after a challenging data lesson that he followed directly from Everyday Mathematics,

Everyday Mathematics is a good program and when you follow correctly, builds strong mathematical foundations for young math learners. I have to continue studying the program and myself to understand why it is that I do what I do. Does that make sense? Hopefully, this study will bring me closer to that realization. I had a great follow up to Friday's lesson today. I taught them the partial-products algorithm and to my surprise, many of the kids liked it. I understand what you meant when we discussed partial sum and partial products. Jessica, Julia, and I were all opposed to it but you noted how it's important for students' sense of estimation. I totally saw it today and unbelievably, I prefer this algorithm over all the other ones I have taught thus far. Also, it is the one we can truly do in our heads and use in real life, as opposed to the standard multiplication algorithm (James's Reflection, 4/30/07).

Because of this confident experience with the partial products algorithm, James chose to show a clip from this lesson at the third group meeting (5/10/07). After showing the clip, Jessica made the following comment: "I was looking at mental math because it is one of my next lessons. I was thinking about cutting it out because of [time], but now that I have seen it, I see how beneficial it is... and how it incorporates other skills." James and Jessica were both able to develop a certain type of knowledge for teaching that enabled them to reflect on the practice, (Ball 1996) that was specifically connecting the mathematics content with the pedagogy. After, commenting on a student's successful use of the partial products algorithm, Julia's knowledge for teaching took on a more varied approach that still supported reflection, "some students need another way to do the problem," (Informal Interview, 5/23/07), which conveys basic acceptance of the mathematics as multi-faceted. Julia followed this interaction with the following statement, "I found myself defending mathematics and why students need to prove why they get an answer in my [university mathematics course]," (e-mail correspondence, 6/6/07). Through involvement in mathematics talk both in her classroom during post observation interviews and group meetings, Julia began to make solid thoughts about mathematics. Based on her increased strength and comfort in mathematics and mathematics knowledge for teaching, Julia was more firmly footed in her understandings of mathematics as a deeply conceptual practice (Ball, 2003).

\subsection{Mathematics Identity}

Through observed teaching experiences and the community of practice, the participants began to be more reflective and aware of their own mathematics identity not only within the classroom but also in the community of practice. This mathematics identity as defined previously is one that consists of a strong mathematical content and pedagogy knowledge and the confidence that comes with this strength. Specifically, this identity can be seen through their knowledge of mathematics content and the confidence they experienced with mathematics teaching, learning, and understanding. The change in the type of discourse and its subject emphasis was seen from Jessica's comment, "I found that I wasn't just looking at their teaching but also looking at the students; there was a balance between our concern for the students ... the mathematical aspects of it as well. I don't know if there was much about our school except in the beginning, when we mentioned stuff like 'our school wants us to do this, or whatever"' (Group Meeting 4, 5/29/07). James agreed that he felt that the participants started to focus more on themselves rather than "outside factors." Given the specific topics discussed in this community of practice, the participants' mathematics identity changed. It is likely that the intentionality of the topics and content of discussion for the community of practice had a direct effect on the identity transformations (Gee, 2000-2001; Lave \& Wenger, 2003).

It is important to note that my involvement in this study contributed somewhat to the change in the other participants' comments and their identity. My role could be defined solely as the participant observer but it was more. My mathematics knowledge and experience in teaching mathematics put me in a position of mentor. Another way to describe my participation is as a "boundary agent" bringing into the community tools and resources that become part of the group's practice (Wenger, 1998). The quotes that follow demonstrate how the participants saw my role as well as the role of the community of practice in their transformations.

“...but I can't emphasize how crucial the consistent feedback from a veteran math teacher and colleagues has really helped to develop me into an effective teacher." (Julia 5/29/07 group meeting) 
"I like being able to learn and gain insight from other people's teaching strategies and ideas." (Jessica 5/29/07 group meeting)

"It kind of made me think even when she wasn't there 'what would [the researcher] say about this?" (James $5 / 29 / 07$ group meeting)

The interaction among people in a learning environment in which functioning in isolation is not a possibility (i.e., working in a community of practice) has led to greater reflection among the teachers. This specific approach to teacher development and learning engenders the participants to learn in a social environment. Furthermore, the positive confident identities the participants have developed in relation to mathematics works in conjunction with their practice, in the context of the community (Darling-Hammond, 1998; Dewey, 1990/1915; Saxe, 2002; Wenger, 1998).

\section{Discussion, Limitations, and Implications}

The understanding of mathematics both in learning and in teaching is informed by one's engagement in the discipline. This engagement could take the form of reflection, practice, and questioning. The extent to which a teacher engages in these practices with mathematics is a determinant of the development of their identity as mathematics teachers. This intentionally formed community of practice helps to establish more positive mathematics teaching identities for the participants.

Through the use of curriculum, observation, and their own experience, the participants made connections between the content of mathematics and the pedagogy of mathematics (Ball, 2003). Jessica, Julia and James explained concepts, interpreted student work, and worked with and adjusted mathematical representations to better understand the mathematics and educate their students, (Hill, et al., 2005).

Building on research in communities of practice (Lave \& Wenger, 2003; Wenger, 1998), mathematics teacher identity (Van Zoest \& Bohl, 2005), identity (Gee, 2000-2001) and teacher learning and knowledge (Ball, 2003; Carpenter et al., 1996; Franke et al., 1998), this study shows that the participants' confidence, reflective practice, and questioning nature lead to the development of a "teacher of mathematics" identity. This participation in a community encourages to the formation and transformation of an identity that is supported by the individual's competence in mathematics and mathematics teaching (Roth, 2006). Although all of these teachers considered themselves new elementary school teachers initially, as the term progressed they began to think of themselves as mathematics teachers, mainly through their ability to reflect on their practice.

Possible limitations of this research include of a short time frame to conduct the study, a community of practice with only 4 participants made up of one researcher and the teachers who volunteered and who were predisposed to improve their teaching of mathematics. A possible limitation of the study is in the methodology, having a researcher as a participant observer. The participant researcher may bias some responses by the participants. Even with these limitations, this study strongly suggests that through involvement in an intentionally created community of practice positive changes in mathematics knowledge, pedagogy and identity occur. Clearly continuous learning is encouraged.

It is important to note that how a new teacher grows and develops as a teacher of mathematics depends on the influences of the teacher's school policies and the professional development they are involved in, as well as the teacher's identity as a mathematics teacher. While case studies such as the case studies described in this study can provide important leads, additional large-scale research is needed to confirm the findings on the effects of communities of practice, inquiry, and learning communities.

I hope this research will lead policy makers to examine their policies with regard to the induction of new elementary teachers into the teaching of mathematics. Although, there is evidence of a movement away from systematic mentoring in the face of budget cuts, the benefits of collaboration among teachers is found to be a valuable asset for in-service teachers, especially new teachers, and should be used to help them transition into the profession. This transition, as studies have shown, is likely to have positive impacts on retaining teachers in the profession and building their content knowledge and knowledge for teaching (Ingersoll \& Smith, 2004; National Commission on Teaching and America's Future [NCTAF], 2005). Instilling in teachers the practice of connecting to mathematics reflectively, confidently and inquisitively will lead to greater collaboration in eliminating the teaching in isolation model. Communities of practice help to support these practices to develop "teachers of mathematics" through the participants' ability to reflect, question, and take ownership of their practice. 
The learning and development of new elementary school teachers as mathematics teachers is a necessary element of their induction into the profession. Using the transformative socially constructed model of induction such as a community of practice should be encouraged and studied further.

\section{References}

Ball, D. L., \& Wilson, S. M. (1990). Knowing the subject and learning to teach it: Examining assumptions about becoming a mathematics teacher. Retrieved October 2004, from http://ncrtl.msu.edu/research.htm

Ball, D. L. (1996). Teacher learning and the mathematics reforms: What do we think we know and what we need to learn. Phi Delta Kappan, 77, 511-518.

Ball, D. L. (2003). What Mathematical Knowledge is Needed for Teaching Mathematics? Paper presented at the Secretary's Summit on Mathematics, U.S. Department of Education, Washington, D.C.

Carpenter, T. P., Fennema, E., \& Franke, M. L. (1996). Cognitively Guided Instruction: A Knowledge Base for Reform in Primary Mathematics Instruction. The Elementary School Journal, 97(1). http://dx.doi.org/10.1086/461846

Cooley, L., Angulo, N., Donoghue, E., Meagher, M., \& Michelli, N. M. (2006). Ethnographic Study of eight New York City Mathematics Teaching Fellows: Graduate Center of the City University of New York.

Common Core State Standards Initiative. (2010). Common core state standards for mathematics. Retrieved from http://www.corestandards.org/Math

Darling-Hammond, L. (1996). The Right to Learn and the Advancement of Teaching: Research, Policy and Practice for Democratic Education. Educational Research, 25(6), 5-17.

Darling-Hammond, L. (1998). Teacher Learning that Supports Student Learning. Educational Leadership, 55, 6-11.

Dewey, J. (1990/1915). The School and Society and the Child and the Curriculum. Chicago: The University of Chicago Press.

Dewey, J. (1997/1933). How We Think. Mineola, NY: Dover Publications Inc.

Drake, C., Spillane, J. P., \& Hufferd-Ackles, K., (2001). Storied Identities: Teacher Learning and Subject-Matter Context. Journal of Curriculum Studies, 33(1), 1-23.

Education Week. (2007). Building Professional Learning Communities. Transcript from on-line chat on Retrieved November 19, $2007 \quad-\quad$ January 15, 2008, from www.edweek.org/chat/2007/11/19/transcript_11_19_2007.html

Enyedy, N., Goldber, J., \& Welsh, K. M., (2006). Complex Dilemmas of Identity and Practice. Science Education, 90(1), 68-93. http://dx.doi.org/10.1002/sce.20096

Everyday Mathematics. (2004). Second Edition Update. Wright Group/McGraw-Hill.

Feiman-Nemser, S. (2001). From Preparation to Practice: Designing a Continuum to Strengthen and Sustain Teaching. Teachers College Record, 103(6), 1013-1055. http://dx.doi.org/10.1111/0161-4681.00141

Franke, M. L., Carpenter, T., Fennema, E., Ansell, E., \& Behrend, J. (1998). Understanding Teachers' Self-sustaining Generative Change in the Context of Professional Development. Teaching and Teacher Education, 14(1), 67-80. http://dx.doi.org/10.1016/S0742-051X(97)00061-9

Gee, J. P. (2000-2001). Identity as an Analytic Lens for Research in Education. Review of Research in Education, $25,99-125$.

Hill, H. C., Rowan, B., \& Ball, D. L. (2005). Effects of Teachers' Mathematical Knowledge for Teaching on Student Achievement. American Educational Research Journal, 42(2), 371-406. http://dx.doi.org/10.3102/00028312042002371

Ingersoll, R. M., \& Smith, T. (March 2004). Do Teacher Induction and Mentoring Matter? NASSP Bulletin, 88(638). http://dx.doi.org/10.1177/019263650408863803

Lave, J., \& Wenger, E. (2003). Situated Learning: Legitimate Peripheral Participation. Cambridge, UK: Cambridge University Press.

McAdams, D. P. (1993). The Stories We Live By: Personal Myths and the Making of the Self. New York: Morrow. 
McDiarmid, G., \& Wilson, S. M. (1991). An Exploration of the Subject Matter Knowledge of Alternative Route Teachers: Can We Assume They Know Their Subject? Journal of Teacher Education, 42(2), 93-103. http://dx.doi.org/10.1177/002248719104200203

National Commission on Teaching and America's Future [NCTAF]. (2005, August). Induction into Learning Communities. Washington, DC: Retrieved May, 2006, from http://www.nctaf.org/wp-content/uploads/NCTAF_Induction_Paper_2005.pdf

NCTM. (1991). Professional Standards. National Council of Teachers of Mathematics.

NCTM. (2000). Principles and Standards for School Mathematics. National Council of Teachers of Mathematics.

NCTM. (2008). Curriculum Focal Points for PreKindergarten through Grade 8 Mathematics. National Council of Teachers of Mathematics.

Remillard, J. (2000). Can Curriculum Materials Support Teachers' Learning? Two Fourth-Grade Teachers' Use of a New Mathematics Text. The Elementary School Journal, 100(4), 331-350. http://dx.doi.org/10.1086/499645

Roth, W.-M. (2006). Identity as Dialectic: Re/making Self in Urban Schooling. In J. Kincheloe, P. Anderson, K. Rose, D. Griffith, \& K. Hayes (Eds.), Urban Education: An Encyclopedia (pp. 143-153). Westport, CT: Greenwood.

Saxe, G. B. (2002). Children's Developing Mathematics in Collective Practices: A Framework for Analysis. The Journal of the Learning Sciences, $11(2 \& 3), 275-300$.

Sfard, A., \& Prusak, A. (2005). Telling Identities: In Search of an Analytic Tool for Investigating Learning as a Culturally Shaped Activity. Educational Researcher, 34(4), 14-22. http://dx.doi.org/10.3102/0013189X034004014

Sherin, M. G., \& van Es, E. A. (2005). Using Video to Support Teachers' Ability to Notice Classroom Interactions. Journal of Technology and Teacher Education. 13, 475-491.

Stigler, J. W., \& Hiebert, J. (1999). The Teaching Gap: Best ideas from the World's Teachers for Improving Education in the Classroom. New York: Summit Books.

Tobin, K., \& Roth, W-M. (2007). Identity in Science: What For? Where To? How? In W-M. Roth, \& K. Tobin (Eds.), Science, Learning, and Identity: Sociocultural and Cultural-historical Perspectives (pp. 339-345). Rotterdam, NL: Sense Publishing.

Van Zoest, L. R., \& Bohl, J. V. (2005). Mathematics Teacher Identity: A Framework for Understanding Secondary School Mathematics Teachers' Learning Through Practice. Teacher Development, 9(3), 315-345. http://dx.doi.org/10.1080/13664530500200271

Vygotsky, L. S. (1978). Mind in Society: The Development of Higher Psychological Processes. Cambridge, MA: Harvard University Press.

Warfield, J., Wood, T., \& Lehman, J. D. (2005). Autonomy, Beliefs and the Learning of Elementary Mathematics Teachers. Teaching and Teacher Education, 21, 439-456. http://dx.doi.org/10.1016/j.tate.2005.01.011

Wenger, E. (1998). Communities of practice: Learning, meaning, and identity. Cambridge: Cambridge University Press. http://dx.doi.org/10.1017/CBO9780511803932

Wilson, S. M., \& Ball, D. L. (1991). Changing Visions and Changing Practices: Patchworks in Learning to Teach Mathematics for Understanding. Retrieved March 14, 2006, from http://ncrtl.msu.edu/research.htm

Wood, T., Cobb, P. \& Yackel, E. (1991). Change in Teaching Mathematics: A Case Study. American Educational Research Journal, 28(3), 587-616. http://dx.doi.org/10.3102/00028312028003587

\section{Copyrights}

Copyright for this article is retained by the author(s), with first publication rights granted to the journal.

This is an open-access article distributed under the terms and conditions of the Creative Commons Attribution license (http://creativecommons.org/licenses/by/3.0/). 